\title{
MANAGEMENT OF E-LABORATORIES - DEVELOPMENT THROUGH BUSINESS PERSPECTIVE
}

\author{
Tarik Mutapčić, Drago Cmuk, Roman Malarić
}

Faculty of Electrical Engineering and Computing, Zagreb, Croatia

\begin{abstract}
This paper presents a design of a future Web based measurement laboratory, by applying new architectural approach considering the state of art of advanced technology as well as the strategy for the future business perspective. Such approach also provides a lot of solutions and applications under the real conditions covering different areas of industrial research, operational analysis and system research methods. The paper discusses the results of preliminary testing using Appreciative Inquiry methodology, that are the basis for conceiving, designing and preparing marketing aspects of an e-laboratories and m-laboratories, considering its cost-effectiveness and multifunctionality of the applied model for a wide range of users. The result of this new approach will completely optimize current " $e$ " and " $m$ " laboratory solutions [1]. Management through business perspective is not only technical development, it also includes educational, humanitarian, and commercial aspects.
\end{abstract}

Keywords: e-Learning, Internet Accessible Laboratory.

\section{E-LEARNING AND STANDARDIZATION}

Online learning takes advantage of the Internet and enables the delivery of just-in-time training online. The main benefit gained from online learning is a higher degree of retention by the learner and an increased efficiency in supplying the learning material. The potential of e-learning to reduce overall training costs is, however, still somewhat debatable, and the "breathtaking" technological revolution in the delivery of education does not seem to have significantly enhanced the learner's overall knowledge. The success of e-learning also depends upon how e-learning is defined.

\section{A. STANDARDS FOR E-LEARNING: WHAT AND WHY}

Standards can be defined as "documented agreements containing technical specifications or other precise criteria to be used consistently as rules, guidelines, or definitions of characteristics, to ensure that materials, products, processes and services are fit for their purpose" (ISO, 2002) [2]. In the context of e-learning technology, standards are generally developed for use in systems design and implementation for the purposes of ensuring interoperability, portability and reusability. These attributes should apply to both the systems themselves and of the content, data and processes they manage. Specifications represent standards early in their development, prior to receiving approval from standards bodies. Specifications can often be experimental, incomplete and rapidly evolving. They capture a rough consensus, and are meant to enable technology development and manage short-term risk. Standards, on the other hand, are much more conclusive, complete, and evolve much more slowly. They should capture general acceptance, can serve regulatory purposes, and be used to manage long-term risk. In e-learning, standards are often multi-part, typically consisting of: 1) a "data" or "conceptual" model which specifies the standard's "normative" content in abstraction; 2) one or more "bindings," which specify how the data model is expressed in a formal idiom, which is most often XML; and (less frequently) 3) an "API" (Application Programming Interface) or "service definition" that defines points of contact between cooperating systems. The development of technical standards in e-learning can be seen as part of the maturation of this recently emergent field or industry.

Since the advent of the personal computer, digital technologies have of course become increasingly common in education --both in distance and classroom education and training settings. However, these technologies have typically been applied in ad hoc and divergent forms: Innumerable courses, course components and systems for managing and 
delivering them have been developed independently of one another, often at great expense. Moreover, this content and these systems are often created in a manner that makes it very difficult, if not impossible, to support their interchange or their successful interoperation. Standards in e-learning address these shortcomings by ensuring the interoperability, portability and reusability of this content and of these systems [3].

\section{E-LABORATORY}

Education is not just the gaining of knowledge (accumulating facts and principles). Science has been built up over the centuries through observation, measurements and experimentation. The students must be able to apply the knowledge they learn to interpret information that is unfamiliar to them, to explain phenomena, and to solve problems. To do this they need the practical skills. This is especially true in teaching electrical measurement topics, and this kind of experience should be given to the students through laboratory work. Experimentation brings the course theory alive, and students can see how unexpected events can affect measurements in a real world. However, due to expensive equipment, necessity for repeating the same experiment many times (because of a big number of students) and insufficient number of qualified teaching personnel, measurement laboratories for didactic purposes are difficult to set up. This makes difficult practical education of students and engineers, especially in the fields of quality control, testing engineering and metrology.

\section{B. THE CHALLENGE OF BUILDING THE INTERNET ACCESSIBLE LABORATORY}

This paper shows new architectural approach and outlines progress to date as well as plans for the future. E-laboratory has to be accessible to students. If that also makes them more accessible to faculty colleagues or industrial partners, so much the better [4-6]. Our principal aim in the eLab project, however, has been to integrate Internet accessible labs as smoothly as possible into students' educational experience with everything that implies about context and the scalability of the endeavor.

This basic priority leads fairly directly to three goals that affect our design:

1. While students are the intended beneficiaries, the people who need the help are the faculty and lab staff who must set up and interface the labs to the Internet. Our most important goal is to provide a software infrastructure that will make it easier and cheaper to make a lab Internet accessible. To the greatest degree possible, we want to do so without making any assumptions about the nature of the lab itself, the pedagogy [7] used by the faculty, or the academic policies of the educational institution using the lab.

An ideal endpoint for the project would be the participation of major lab equipment and software vendors (e.g., Agilent, National Instruments) [8] to provide Internet-ready equipment and software. In fact, National Instruments already provides a LabView web browser client and server-side software to connect to it. These modules, however, are better adapted for factory automation behind a firewall than the open Internet. We must reach beyond a purely academic environment to engage the active cooperation of industry, and we should focus on the part of the problem that we understand: how to use experiments to reinforce pedagogy and how to integrate online labs with students' work habits. We should avoid duplicating or competing with industry efforts to create technology that they offer to academic institutions at deep discounts.

2. We should plan for an environment that can host or offer multiple online labs semester after semester. The software should not increase the administrative load of either the course or lab staff. Simply put, Internet access opens lab equipment to a wide audience. We must make sure that the software scales.

There are also clear advantages to predictable interfaces and administrative procedures. If a student uses more than one Internet accessible lab, she should find using the second more natural after using the first. Domain specific aspects of lab equipment and procedures may differ, but the methods a student uses to reserve or connect to a lab, to store or review results, etc, should remain as uniform as possible.

3. The concept of Internet accessible labs encourages cross-institution cooperation. One can easily imagine students at one university using a laboratory made accessible by a second university. Schools or universities may decide to share the cost of an expensive laboratory and physically establish it at a convenient location. One can also imagine government participation that would offer limited access to national laboratories or facilities like the International Space Station. In time, as online labs proliferate, we may require a discovery process by which a faculty member (or a student) can locate an online lab that offers a particular experiment or technology.

These potential uses require that the software architecture separates lab users from lab providers. It also suggests that the architecture should support priorities of use, and eventually distributed resource accounting. We believe the ideal scheme would be one in which laboratory staff could determine what proportion of lab time would be devoted to each 
category of use but delegate the mechanisms of access by category and institution to servers and policy controlled by the institutions providing the lab users (students). For example, a particular MIT laboratory might decide to offer $10 \%$ of all access to students at Stanford and $20 \%$ of night access to a consortium of universities funded under an NSF initiative. But MIT should not manage or even be cognizant of how Stanford or the NSF Consortium were allotting their proportional access to individual students.

\section{WHERE'S THE LEVERAGE?}

At this point it is reasonable to ask, given the immense variety of laboratory experiments and equipment, whether they share sufficient characteristics so that they can be supported by a common software infrastructure. How can we begin to organize the near infinite variety of ad hoc laboratory configurations and procedures so we can model them and match them to a software strategy? The fact that hardware vendors now provide low level control of lab devices via industry standard protocols such as GPIB doesn't address the issue of a high-level software architecture. Packages like National Instruments' LabView and its associated lower level libraries provide visualization and interface support, but they do not integrate with the types of enterprise scale software that universities are using to manage courses.

We believe the leverage lies in providing general support for the framing and maintenance of a lab session while leaving details of the lab interface and control to domain specific experts or to vendors like National Instruments. That is, we want to distinguish the parts of using an online lab that are specific to a particular piece of lab equipment or to the specific series of tasks that comprise a particular experiment from the generic tasks that proceed, manage, and follow any lab session.

The student will usually need to authenticate himself to the lab software. The student's online identity may well govern the labs that are made available through subsequent menus. For experiments of some duration, the student may need to have previously reserved the online lab. Results will need to be stored, analyzed, compared, or printed. The system may encourage collaborative work using standard application sharing and communication tools. The system should allow the student to forward a $\log$ of lab activity to a staff member to enlist their help with a problem. These capabilities are generic and transcend the individual experiment. Not all online experiments will require all of them, but most online experiments will require some of them.

\section{DEVELOPMENT AND BUSINESS PERSPECTIVE}

A challenge is also to conceive, design and prepare marketing aspects of an e-laboratory considering its cost-effectiveness and multifunctionality of the applied model for a wide range of users. This asks for a specific management of educational, humanitarian, and commercial use. It also asks for organization of a specific management model integrating an overall process and business organization of such an e-laboratory. A task defined in this way demands that an adequate cybernetic model be developed in order to achieve synergy of technological, educational and commercial capacities of an e-laboratory.

\section{A. CONCEPT AND OBJECTIVES}

1. Depending on the original purpose and invested engineering effort, a prototype of the elaboratory could be approached as any other business project intended for global market. However, in order for such a project to become an actual company, a business plan, marketing strategy and laboratory management model need to be developed.

2. If the capacities of the e- laboratory and its development are to be clearly presented to industrial users, the professional management tools and methods should be used to develop an adequate marketing strategy, ranging in approach from the demand market cultivation to the commercial conditions of supply.

3. Although, at the moment, the e-laboratory prototype has the possibilities of a pilot project, primarily for educational and humanitarian purposes, its key characteristics such as accessibility, real-time operation, simple use, logistic and economic advantaged. This gives an elaboratory vast possibilities of use and its development in direction of a company. A real challenge for the management is to catch up with development and technological trends and develop an array of products and services. The result will be quick, technologically superior, cost-effective and quality response to the user needs, regardless of their location in the global market.

4. Based on an idea that the e-laboratory prototype is a case study of innovative advancement of scientific and technological work, and assuming that it paves a path for the future of the applied research, the aim of this paper is to develop an adequate model for the e-laboratory management. Such a model should respond to a key question how to turn an essentially scientific academic pioneering project into a successful company. 


\section{B. METHODOLOGY - APPRECIATIVE INQUIRY}

By information obtained from published papers and operation of the e-laboratory on one hand, and combining those with business opportunities can prove to be successful combination of scientific and technological properties of the e-laboratory with the method and tools of the knowledge management and system engineering used to manage launching of innovative projects.

Appreciative Inquiry [9] is the study and exploration of what gives life to human systems when they are at their best. It is an organization development methodology based on the assumption that inquiry into and dialogue about strengths, successes, values, hopes and dreams is itself transformational. Indeed, organizations, businesses and communities can benefit by greater appreciation. Around the global, people hunger for recognition. They want to work from their strengths on tasks they find of value.

Appreciative Inquiry is about more than appreciation, recognition, and enhancement of value. It's also about inquiry. Inquiry refers to the acts of exploration and discovery. It implies a quest for new possibilities, being in a state of unknowing, wonder and a willingness to learn. It implies an openness to change. Inquiry is a learning process for organizations as well as for individuals. Seldom do we search, explore or study what we already know with certainty. We ask questions about and query into areas unfamiliar to us. The act of inquiry requires sincere curiosity and openness to new possibilities, new directions and new understandings. We cannot have "all the answers," "know what is right," or "be certain" when we are engaged in inquiry. The spirit of inquiry is the spirit of learning.

The Appreciative Inquiry (after the method of D. Whitney, Case Western University, USA) will also be carried out on a target sample of 20 prospective users of products and services of the e-laboratory in order to get a quality feedback for evaluation of interest, cost-benefit and assumed market demand.

\section{CONCLUSION}

Training on real measurement equipment is very helpful to test theoretical understanding of measuring the electrical quantities. How to incorporate new technologies that are offering new possibilities for designing virtual and e-laboratories with needed hands-on laboratory, if they want to give students necessary practical work they will need once they are out of the universities [10]. The best way is to use the use new e-laboratories whenever possible, but also to give students enough practical work with real equipment.

The challenges of the 21 st century will require new ways of thinking about and understanding the complex [11], interconnected and rapidly changing world in which we live and work. In the last twenty years, rapid advances in high-speed computing have created a revolution in the scientific understanding of complex systems. We now have the ability to move beyond the old reductionist paradigm; to look at whole systems; to study the interactions of many interdependent variables and to explore the underlying principles, structure and dynamics of complex physical, biological and social systems.

\section{REFERENCES}

[1] http://lesim1.ing.unisannio.it

[2] Intro e-learning standardization, http://www.cancore.ca

[3] http://www.educatorscorner.com/

[4] M. Bertocco, F. Feraris, C. Offelli, M. Parvis, Training of programmable instrumentation: a student laboratory, $14^{\text {th }}$ IMEKO World Congress, Tampere, Finland, vol. 2, 1997, pp.13-17

[5] G.Canfora, P. Daponte, S. Rapuano, Remotly accessilble laboratory for electronic measurement teaching, Computer Standards \& Interfaces, 26, (2004), pp. 489-499

[6] P. Arapia, A. Baccigalupi, F. Cennamo, P. Daponte, A distributed measurement laboratory on geografic network, Proc. of $8^{\text {th }}$ IMEKO International Symposium on "New Measurements and Calibration Methods of electrical Quantities and instruments", Budapest, Hungary, 1996, pp. 294-297.

[7] J.M. Thiriet, M. Robert, M.J. Martins, M. Hoffmann, Pedagogical resources reachable via Internet for teaching intelligent instruments: developments within a European thematic network, IEEE IMTC 2002, Anchorage, USA, 2002, pp. 1475-1479.

[8] National Instruments. http://www.ni.com

[9] Corporation for Positive Change, http://www.positivechange.org/

[10] Internet access to real labs, http://icampus.mit.edu/iLabs/default.aspx

[11] ComplexityScienceSurvey http://www.complexsys.org 


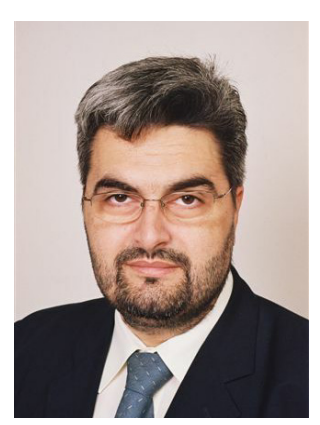

Tarik Mutapcic was born in Zenica, BiH,on July 26,1967. In 1994 he achieved the master's degree in Department of Electric Machines, Drives and Automation from Faculty of Electrical Engineering and Computing, University of Zagreb presenting a thesis work titled * "Mine elevator control system upgrading using PLC".Through EMBA program since 2003, his research field was entrepreneurship and technology commercialization, in which he creates programs to enable the next generation of business leaders to combine their passion for technology with the management ability to succeed in today's challenging global marketplace. At the present time he collaborates with the Laboratory of Signal Processing and Measurement Information of the University of Sannio, Benevento and Faculty of Electrical Engineering and Computing, University of Zagreb. Primary activities are in area of Management of Remote Laboratories - initiatiation, design and guide development of innovative remote laboratory for commercial success.

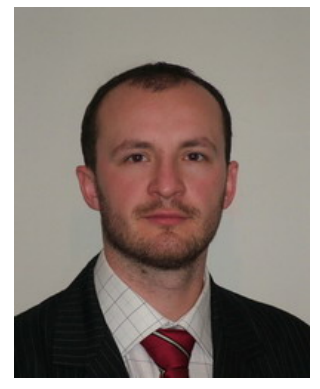

Drago Cmuk is a researcher and assistant at the Faculty of Electrical Engineering and Computing, Zagreb, Croatia and Faculty of Engineering, Benevento, Italy. He graduated 2003. and started international postgraduate studies and scientific work on the field of remote laboratories 2004 mentioned universities. He is working as assistant on the group of courses on Electric Measurements and Quality management. Currently he is writing dissertation on the topic of optimization of E-learning and m-learning methods in metrology education.

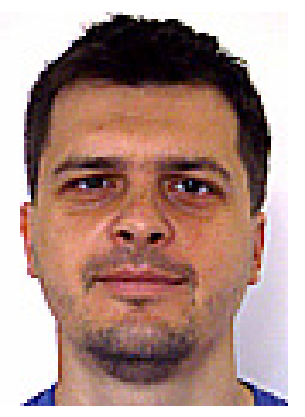

Roman Malarić was born in February, 1971, in Zagreb, Croatia. He received the $B$. S. Degree from University of Zagreb, Croatia, in 1994 in the field of radio communications. He earned M. Sc. and Ph.D. degrees from the same university, in 1996 and 2001 respectively. In 2004 he become assistant professor at Zagreb University, Faculty of Electrical Engineering and Computing, Department of EE Basics and Measurement, where his primary interest is development of precise measurement methods for electrical quantities, and the automatization of measurement methods by computers and virtual instrumentation. 